\title{
A High Frequency-Link Bidirectional DC-DC Converter for Super Capacitor-Based Automotive Auxiliary Electric Power Systems
}

\author{
Tomokazu Mishima ${ }^{\dagger}$, Eiji Hiraki*, and Mutsuo Nakaoka** \\ ${ }^{\dagger}$ Dept. of Electrical Eng. and Information Sci., Kure National College of Technology, Hiroshima, Japan \\ * Dept. of Electrical and Electronics Eng., Yamaguchi University, Ube, Japan \\ ** The Electric Energy Saving Research Center, Kyungnam University, Masan, Korea
}

\begin{abstract}
This paper presents a bidirectional DC-DC converter suitable for low-voltage super capacitor-based electric energy storage systems. The DC-DC converter presented here consists of a full-bridge circuit and a current-fed push-pull circuit with a high frequency $(\mathrm{HF})$ transformer-link. In order to reduce the device-conduction losses due to the large current of the super capacitor as well as unnecessary ringing, synchronous rectification is employed in the super capacitor-charging mode. A wide range of voltage regulation between the battery and the super capacitor can be realized by employing a Phase-Shifting (PS) Pulse Width Modulation (PWM) scheme in the full-bridge circuit for the super capacitor charging mode as well as the overlapping PWM scheme of the gate signals to the active power devices in the push-pull circuit for the super capacitor discharging mode. Essential performance of the bidirectional DC-DC converter is demonstrated with simulation and experiment results, and the practical effectiveness of the DC-DC converter is discussed.
\end{abstract}

Key Words: Bidirectional DC-DC converter, High Frequency (HF)-link, Push-pull circuit, S.C. charging mode, S.C. discharging mode, Super Capacitor (S.C.), Synchronous rectification

\section{INTRODUCTION}

Researches on high performance bidirectional DC-DC converters have been gaining momentum in industry, residential and aerospace environments [1]-[4]. In particular, for advanced and next generation vehicles such as Electric Vehicles (EVs) and Hybrid Vehicles (HEVs), this type of DC-DC converter is playing a key role for establishing an efficient power conversion and supplying system [5].

Nowadays, demands for the dual DC-voltage power systems as illustrated in Fig. 1 are surging for EVs, HEVs and other low $\mathrm{CO} 2$-emission vehicles. They are even being utilized in a conventional combustion engine car named More Electric Vehicles (MEVs) [1].

In the electric power architecture illustrated in Fig. 1, the high voltage battery, e.g. $42 \mathrm{~V}$ or $288 \mathrm{~V}$, is employed as the main DC bus-line to supply more power to the loads as well as to reduce the volume of the electric wire harness [1], [2]. In this scheme, an auxiliary energy storage device such as a super capacitor (S.C.) is regarded as a key device for assisting the operation of the main battery against the repetitive

\footnotetext{
Manuscript received Aug. 20, 2009; revised Dec. 6, 2009

$\dagger$ Corresponding Author: mishima@kure-nct.ac.jp

Tel: +81-823-73-8469, Fax: +81-823-73-8469, Kure Nat'l College of Tech

* Dept. of Electrical and Electronics Eng., Yamaguchi Univ., Japan

** The Electric Energy Saving Research Center, Kyungnam Univ., Korea
}

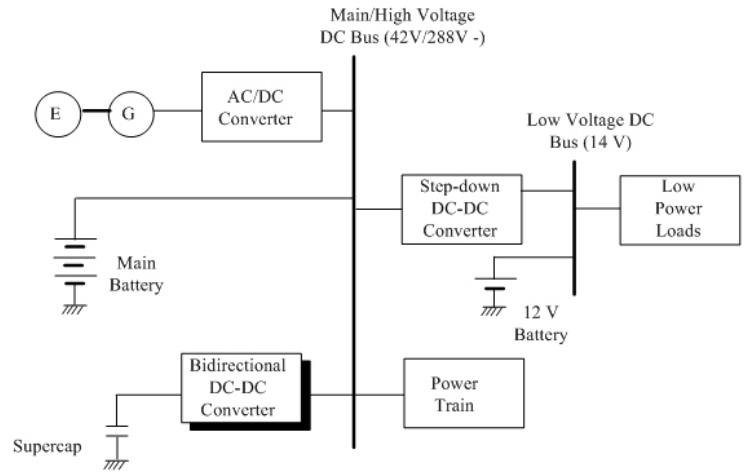

Fig. 1. Dual DC bus-voltage architecture in advanced electric vehicles (EVs, HEVs).

charging/discharging operation and abrupt energy demands from the loads.

The bidirectional DC-DC converters developed for S.C. interfacing circuits up to the present time have been mainly nonisolated bidirectional DC-DC converters (current reversible DC choppers) [6], [7]. The non-isolated type circuit topology generally has some advantages such as a simple and light circuit configuration due to the transformer-free circuit topology. Since the tolerable and operating voltage of a S.C. cell is relatively low, e.g. $2.7 \mathrm{~V}$, it is typical that a large 


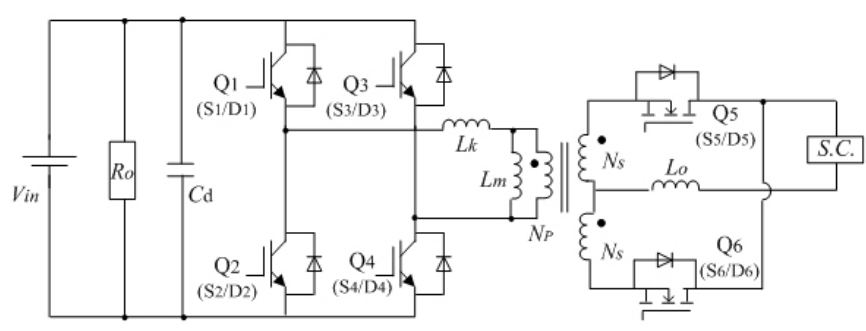

Fig. 2. Proposed HF-link bidirectional DC-DC converter for super capacitor interface.

volume of S.C. cells are connected in series in order to boost the terminal voltage of the S.C.-bank so that no large voltage difference between the two power sources takes place. The series connection of many S.C. cells may trigger some drawbacks such as an increase in ESR (Equivalent Series Resistance) and a decrease in the capacitance of the total S.C. bank. Moreover, installation of additional voltage-balancing circuits is required in parallel with the S.C. cells, and this inherently causes power losses in the total power conversion scheme as well as increase in the S.C. bank size. This leads to deterioration in the energy utilization of the S.C. cells.

Several bidirectional DC-DC converter topologies for low voltage/large current power conversion have been presented so far for power supplies in industry, communication and information facilities etc [2]-[4], [7], [9]. However, there are few proposals that are specified for a S.C. interface power converter under the low voltage condition.

As a new approach for creating a simple and versatile power converter for a S.C. interfacing circuit suitable for the low voltage condition, a HF transformer isolation-type bidirectional DC-DC converter topology is newly developed and its performance is evaluated in this research.

This paper is organized as follows: First, the circuit configuration is introduced. Then the operation principle of the proposed bidirectional DC-DC converter is explained. Next, the operations and the performance characteristics of the proposed bidirectional DC-DC converter are investigated by computer simulations. Finally, the validity of the converter topology is demonstrated with experiments using a prototype of the proposed DC-DC converter.

\section{CIRCUIT TOPOLOGY AND OPERATION PRINCIPLE}

\section{A. Circuit configuration}

The proposed bidirectional DC-DC converter topology is shown in Fig. 2.

The primary power source (main battery or DC bus line) $V_{\text {in }}$ supplies power to the load $R_{o}$ in the normal condition. In the case of a fault in $V_{i n}$ and the upsurge of power demand from $R_{o}$, the stored energy in the S.C. is delivered to the primary side.

In the S.C. charging mode, the full bridge circuit in the primary side operates as an inverter, and the push-pull circuit rectifies and delivers power to the S.C. by synchronous rectification of $S_{5}$ of $Q_{5}$ and $S_{6}$ of $Q_{6}$.
In the S.C. discharging mode, the push-pull circuit operates as an inverter, and the full bridge circuit works as a rectifier.

The motivations for employing a push-pull circuit can be validated by the following: (i) The S.C. is well suited to a current source type power converter. As a result, no bulky smoothing capacitor exists for the output side in the proposed bidirectional DC-DC converter. (ii) Since the operating frequency of the current through the output smoothing inductor $L_{o}$ can naturally double the converter operating frequency, the size and volume of the output smoothing inductor $L_{o}$ can be reduced effectively.

In the full bridge circuit configuration in the primaryside power stage, Phase-Shifted Pulse Width Modulation (PS$\mathrm{PWM}$ ) can be applied to the active switches $\mathrm{Q}_{1}-\mathrm{Q}_{4}$. Thus, the output voltage and output power regulation are performed by the PS-PWM scheme in $\mathrm{Q}_{1}-\mathrm{Q}_{4}$ for the S.C. charging mode.

In the S.C. discharging mode, the shortcut period of the secondary windings of the $\mathrm{HF}$ transformer is adjusted by changing the overlapping ON-term of $S_{5}$ and $S_{6}$. In the gate pulse sequence applied in the bidirectional DC-DC converter, the ON duty-cycles of $\mathrm{S}_{5}$ and $\mathrm{S}_{6}$ should be larger than $50 \%$.

\section{B. S.C. charging mode operation}

The converter operating waveforms in the S.C. charging mode are schematically illustrated in Fig. 3 without consideration for the dead time in the full bridge circuit. In the S.C. charging mode, the output power, i.e. the S.C. charging current is controlled by the PS-PWM of the gate signals for $S_{1}-S_{4}$ in the full bridge circuit.

The operation mode is divided into four steps as follow:

$\left[t_{0}-t_{1}\right]: \mathrm{S}_{4}$ of $\mathrm{Q}_{4}$ is turned-on at $t_{0}$ while $\mathrm{S}_{1}$ of $\mathrm{Q}_{1}$ is in the on-state. Accordingly, the power from $V_{i n}$ is delivered to the loads $R_{o}$ via the HF transformer, and the current thorough the output inductor $L_{o}$ rises linearly.

$\left[t_{1}-t_{2}\right]: \mathrm{S}_{1}$ of $\mathrm{Q}_{1}$ is turned off at $t_{1}$ while $\mathrm{S}_{4}$ remains in the on-state. At the same time, $S_{6}$ of $Q_{6}$ in the push-pull circuit is turned on, while $S_{5}$ of $Q_{5}$ remains in the on-state. In this interval, the zero voltage duration across the primary winding of the HF transformer appears, and no power is transferred to the output terminal. In the secondary side, the energy stored on $L_{o}$ freewheels through $\mathrm{S}_{5}$ and $\mathrm{S}_{6}$, and $i_{L o}$ linearly decreases.

$\left[t_{2}-t_{3}\right]:$ At $t_{2}, \mathrm{~S}_{4}$ of $\mathrm{Q}_{4}$ is turned off, and $\mathrm{S}_{3}$ of $\mathrm{Q}_{3}$ turnson in the complementary way. At the same time, $S_{5}$ of $Q_{5}$ is turned off while $\mathrm{S}_{6}$ of $\mathrm{Q}_{6}$ remains in the on-state. The converter operation during this interval is similar to the one in the interval of $t_{1}-t_{2}$ except that the primary winding of the HF transformer is reversely polarized.

$\left[t_{3}-t_{4}\right]$ : At $t_{3}, S_{2}$ is turned-off, and $S_{1}$ is turned on in the complementary way. In addition, $S_{5}$ is turned on while $S_{6}$ remains on. The operation in this stage is similar to the one in $t_{1}-t_{2}$, so the stored energy in $L_{o}$ freewheels through $S_{5}$ and $\mathrm{S}_{6}$ with the secondary winding of the HF transformer shorted, consequently $i_{L o}$ linearly decays. After $\mathrm{S}_{6}$ is turned off, the next cycle begins while $S_{5}$ remains in the on-state at $t_{4}$.

In the S.C. charge mode, the operation manner of the current-fed push pull converter is similar to the step-down converter, as follow: 


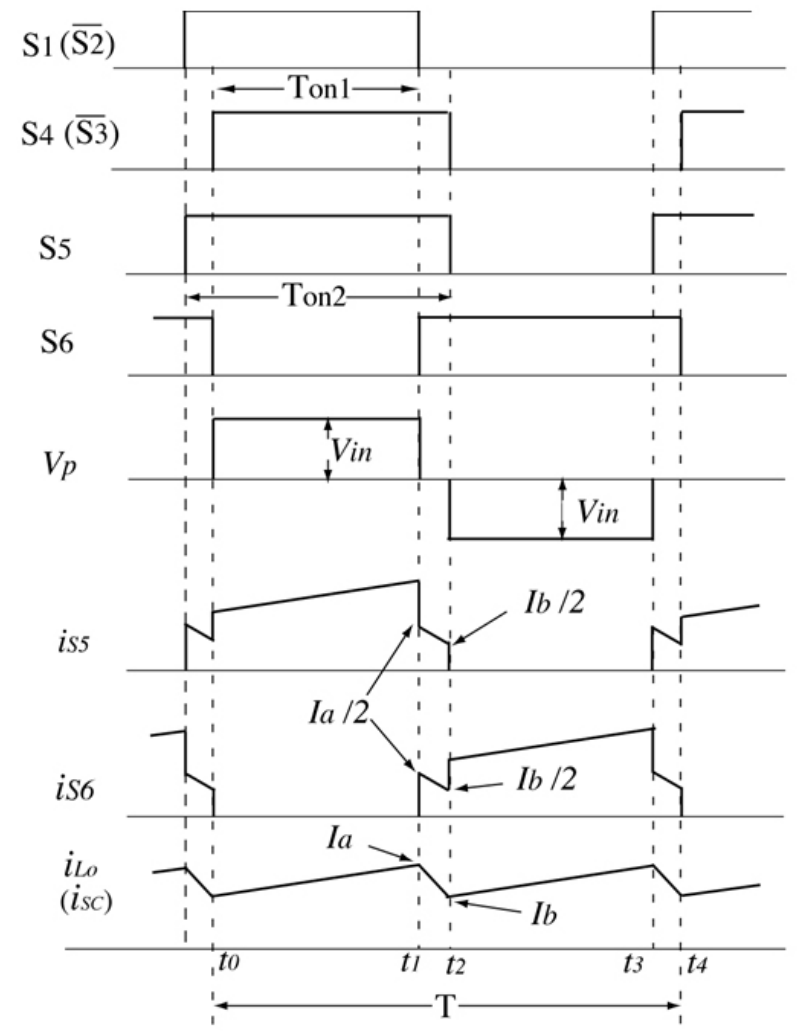

Fig. 3. Relevant voltage and current waveforms in S.C. charging mode.

$$
V_{s c}=\frac{2 N_{s}}{N_{p}} \cdot D V_{i n}, \quad D<0.5
$$

where $\mathrm{D}$ is defined by $T_{o n 1} / T$ in Fig. 3 .

\section{S.C. discharging mode operation}

In the S.C. discharging mode, one-switching period is divided into the four stages as depicted in Fig. 4. Similar to the aforementioned description, the dead time of each switch-leg as well as the diode reverse-recovery currents are not taken into consideration in the following explanation.

[ $\left.t_{0}-t_{1}\right]:$ At $t_{0}, S_{5}$ is turned-on while $S_{6}$ remains in the onstate. At the same time, $\mathrm{D}_{3}$ of $\mathrm{Q}_{3}$ and $\mathrm{D}_{4}$ of $\mathrm{Q}_{4}$ are reversely biased. Since the HF transformer winding of the push-pull circuit is shorted, the inductor $L_{o}$ stores energy and the current $i_{L o}$ linearly increases. Thus, the current is equally shared by $\mathrm{S}_{5}$ and $\mathrm{S}_{6}$, and no power is delivered to the primary-side power source $V_{i n}$ and the load $R_{o}$.

[ $\left.t_{1}-t_{2}\right]$ : At $t_{1}, \mathrm{~S}_{6}$ is turned-off while $\mathrm{S}_{5}$ is in the on-state. At the same time, $\mathrm{D}_{1}$ of $\mathrm{Q}_{1}$ and $\mathrm{D}_{4}$ of $\mathrm{Q}_{4}$ are forward-biased. In this interval, the energy stored in $L_{O}$ during the previous interval, is delivered to $V_{i n}$ and $R_{o}$. As a result, $i_{L o}$ through $L_{o}$ rises linearly during this interval.

$\left[t_{2}-t_{3}\right]:$ At $t_{2}, S_{6}$ is turned-on while $S_{5}$ remains in the onstate. At the same time, $\mathrm{D}_{1}$ of $\mathrm{Q}_{1}$ and $\mathrm{D}_{4}$ of $\mathrm{Q}_{4}$ are reversely biased. The circuit operation in the interval is similar to that in $t_{0}-t_{1}$. Thus, $i_{L o}$ increases linearly due to the stored energy in $L_{o}$, and no power is transferred to $V_{i n}$ and $R_{o}$.

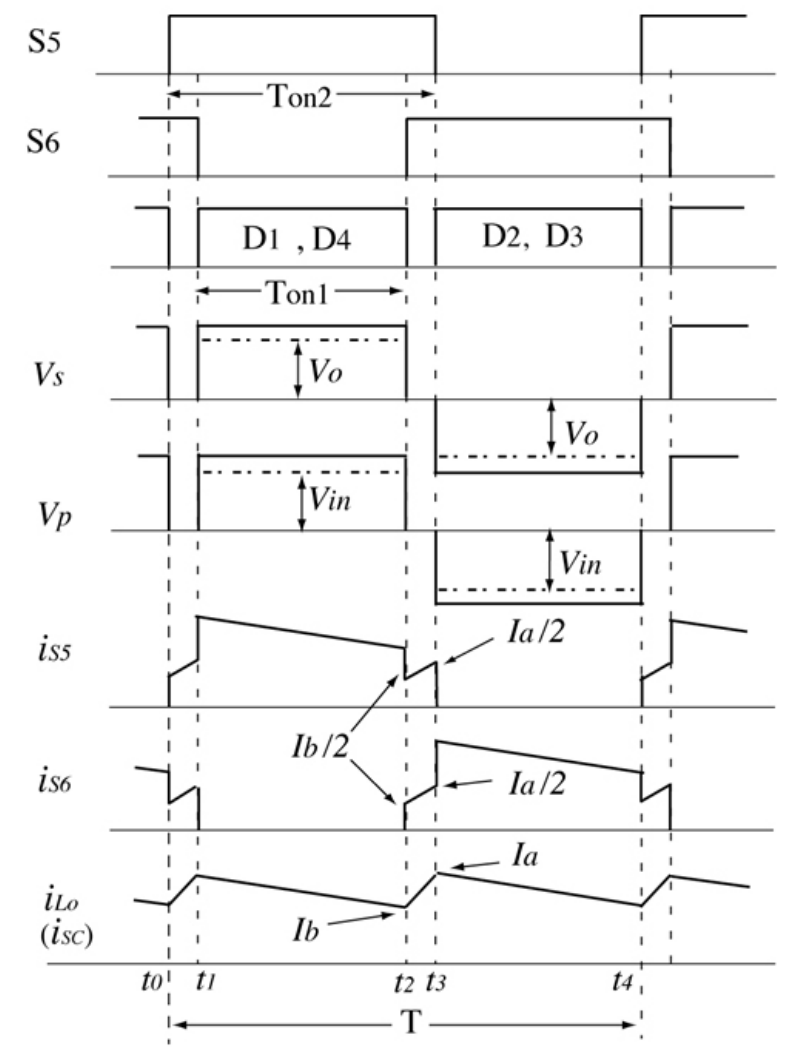

Fig. 4. Relevant voltage and current waveforms in S.C. discharging mode.

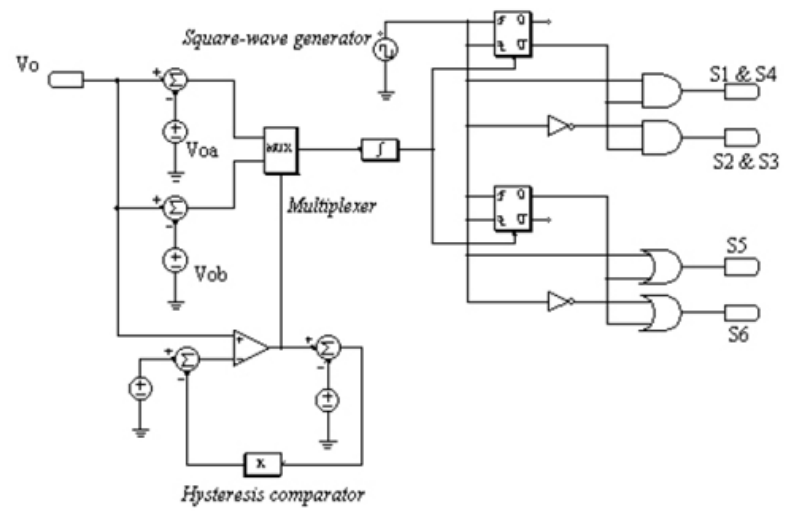

Fig. 5. Circuit diagram of the S.C. charge/discharge mode controller.

[ $\left.t_{3}-t_{4}\right]$ : At $t_{3}, \mathrm{~S}_{5}$ is turned off while $\mathrm{S}_{6}$ is in the on-state. At the same time, $\mathrm{D}_{2}$ of $\mathrm{Q}_{2}$ and $\mathrm{D}_{3}$ of $\mathrm{Q}_{3}$ are forward biased. In this stage, the energy stored in $L_{o}$ during the previous interval is delivered to $V_{i n}$ and $R_{o}$. Thus, the circuit operation in this interval is similar to that in $t_{1}-t_{2}$. After $S_{5}$ is turned-on while $\mathrm{S}_{6}$ remains in the on-state at $t_{4}$, the next cycle begins.

In the S.C. discharging mode, the operation manner of the push pull circuit is similar to the step-up converter, as given by:

$$
V_{s c}=\frac{N_{s}}{N_{p}} \cdot \frac{V_{0}}{2\left(1-D^{\prime}\right)}, \quad D^{\prime}>0.5
$$

where D' is defined by $T_{o n 2} / T$ in Fig. 4. Therefore, the discharging current from the S.C. is regulated by controlling 


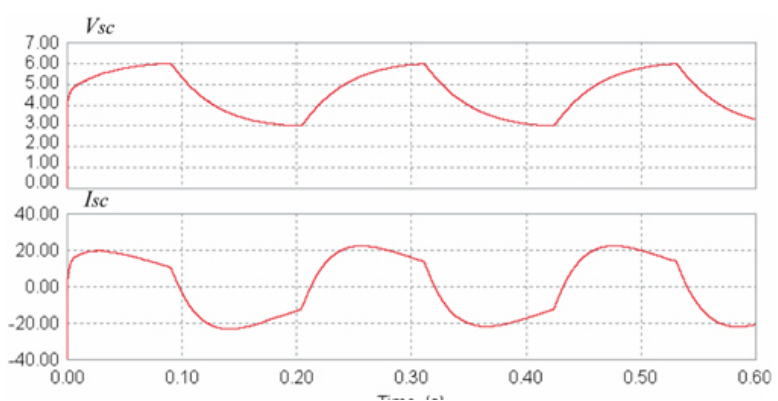

Fig. 6. Simulated operating waveforms for S.C. charging/discharging mode cycle.

the overlapping pulse widths for $S_{5}$ and $S_{6}$.

\section{CONTROL SCHEME FOR S.C CHARGING/DISCHARGING MODE SELECTION}

TABLE I

Circuit Parameters of Experimental Prototype

\begin{tabular}{|c|c|c|}
\hline \hline Parameter & Symbol & Value \& Unit \\
\hline \hline Capacitance of S.C & $C_{s c}$ & $\begin{array}{c}450[\mathrm{~F}] \\
\text { (four-cells series) }\end{array}$ \\
\hline ESR of S.C. & $R_{s c}$ & $4.5[\mathrm{~m} \Omega]$ \\
\hline Main Battery & $V_{i n}$ & $50[\mathrm{~V}]$ \\
\hline S.C. Maximum Voltage & $V_{o m a x}$ & $10.8[\mathrm{~V}]$ \\
& & $(2.7[\mathrm{~V}] / \mathrm{cell})$ \\
\hline HF Transformer Turn Ratio & $N_{T}\left(=N_{P} / N_{S}\right)$ & 5 \\
\hline Link Inductor & $L_{o}$ & $60[\mu \mathrm{H}]$ \\
\hline Switching Frequency & $f_{s}$ & $60[\mathrm{kHz}]$ \\
\hline
\end{tabular}

TABLE II

SPECIFICATION OF S.C. CELL

\begin{tabular}{|c|c|}
\hline \hline Parameter & Value \& Unit \\
\hline \hline Rated Capacitance & $1350[\mathrm{~F}]$ \\
\hline Rated Voltage (DC) & $2.7[\mathrm{~V}]$ \\
\hline Normalized ESR (DC) & $1.5[\mathrm{~m} \Omega]$ \\
\hline Specific Energy Density & $6.5 \mathrm{Wh} / \mathrm{kg}$ \\
\hline Specific Power Density & $5.5 \mathrm{~kW} / \mathrm{kg}($ @2.7[V]) \\
\hline Continuous Charge-Discharge Current & $60[\mathrm{~A}]$ \\
\hline Volume & $0.15[\mathrm{l}]$ \\
\hline
\end{tabular}

The S.C. charging and discharging cyclic operation of the proposed bidirectional converter are evaluated by simulations. The schematic diagram of the S.C. charging/discharging mode selector is illustrated in Fig. 5.

The principle parameters in the simulation circuit model are: $\operatorname{Csc}=450[\mathrm{~F}]$, Rsc $\left(\mathrm{ESR}\right.$ of S.C.) $=4.5[\mathrm{~m} \Omega], V_{s c}(\max )$ $=10.8[\mathrm{~V}], V_{i n}=42[\mathrm{~V}], L_{o}=50[\mu H], C_{o}=500[\mu F]$, $\mathrm{NT}(\mathrm{Np} / \mathrm{Ns})=5$ and the switching frequency fs $=60[\mathrm{kHz}]$. The parameters of the S.C. cell are modeled on the actual product (high power electric double layer capacitors for EV applications PSLF-1350, produced by Power Systems Co. LTD.), which is used for the experimental verifications as discussed later.

In this simulation, the S.C. operating voltage is limited from $V_{O L}=3[V]$ to $V_{O H}=6[V]$ in order to shorten the calculation time.

The simulation waveforms are shown in Fig. 6. The simulation waveforms indicate that the mode-exchanging of the

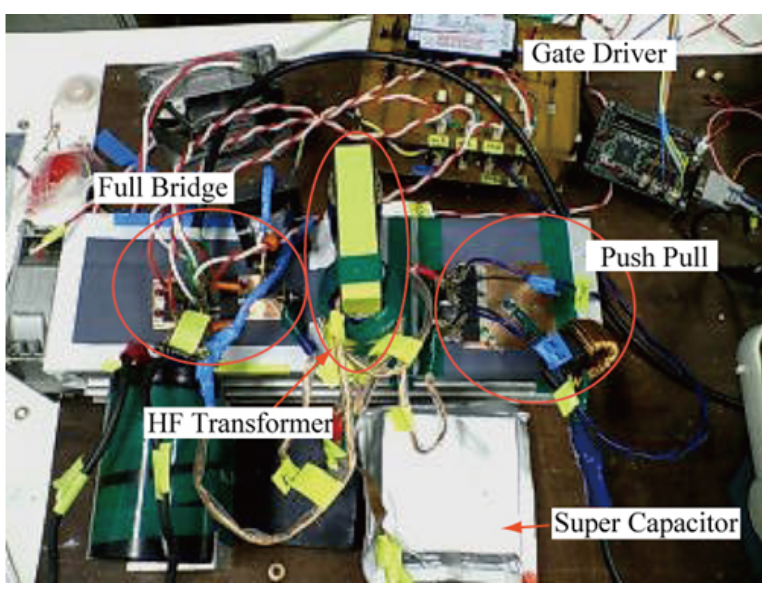

Fig. 7. Laboratory prototype and experimental setup.

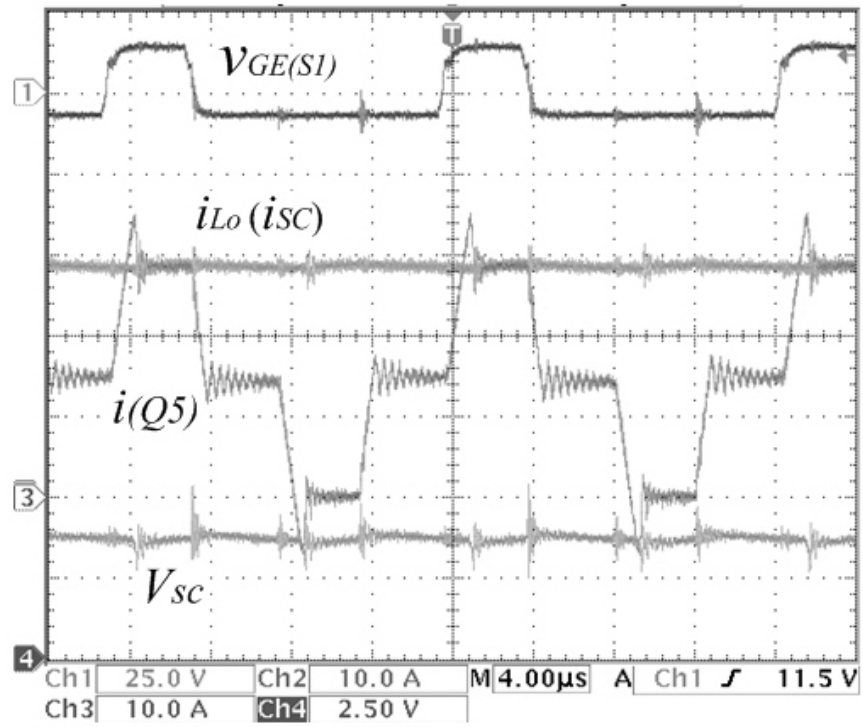

Fig. 8. Measured repetitive circuit operation waveforms in S.C. charging mode.

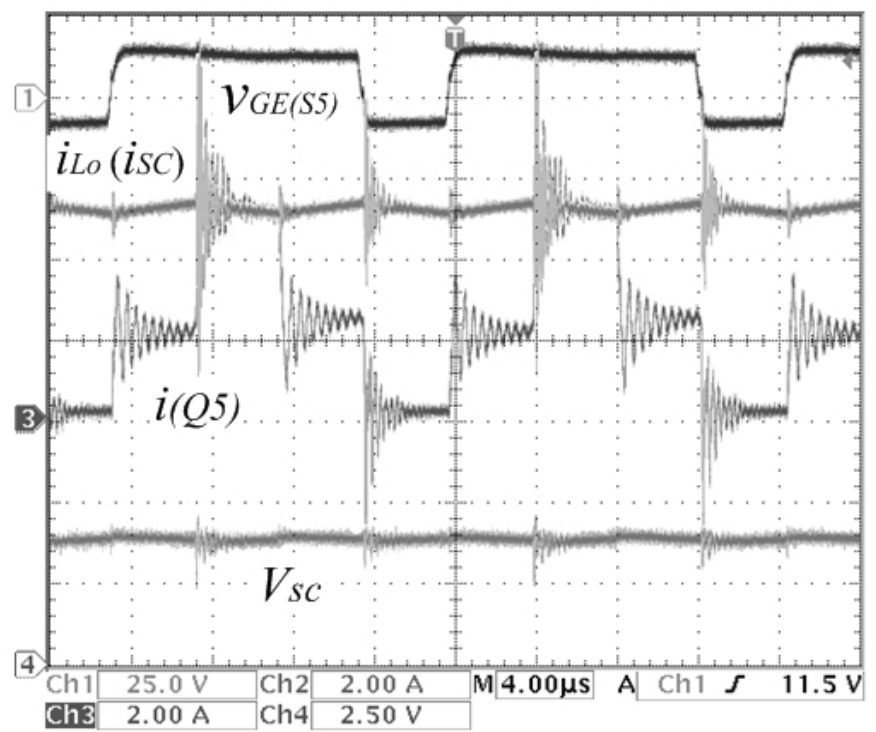

Fig. 9. Measured repetitive circuit operation waveforms in S.C. discharge mode. 


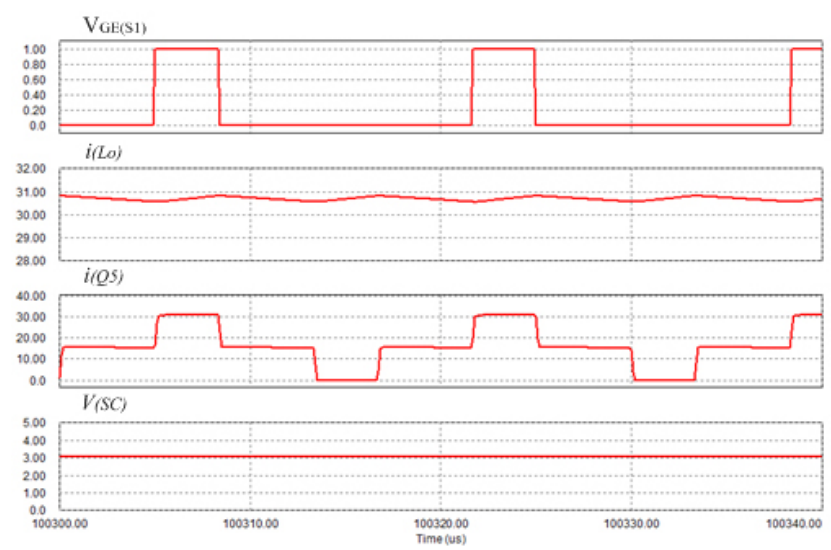

(a) Charging mode

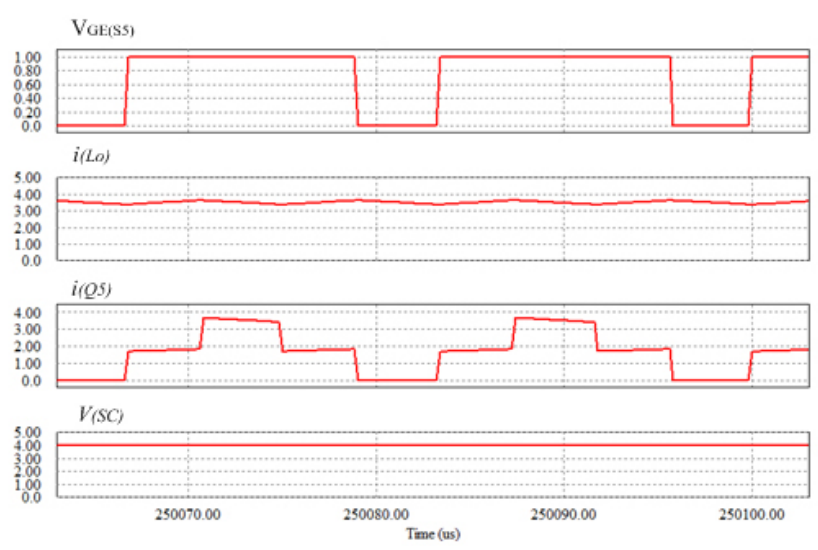

(b) Discharging mode

Fig. 10. Simulated waveforms.

charging and discharging can be determined from the S.C. voltage as well as the battery power conditions. It is also proven that the current fed push-pull circuit topology is useful for the repetitive charging and discharging cycle of the main battery.

\section{EXPERIMENTAL RESULTS}

\section{A. Specification of experimental prototype}

The performance of the proposed bidirectional DC-DC converter for a S.C. interfacing power conditioner is evaluated in an experiment with a $1.2[\mathrm{~kW}]-60[\mathrm{kHz}]$ prototype. The exterior appearance of the laboratory prototype is depicted in Fig. 7. The specifications of the experimental set-up are indicated in Table 1. In the experiment, the S.C. cells developed for EVs are used, the specifications of which are indicated in Table 2 .

In this laboratory prototype, two-in-one IGBT modules (Mitsubishi CM100DU-12F) are employed for the primaryside full bridge circuit. And, the bidirectional active switches $\mathrm{Q}_{5}$ and $\mathrm{Q}_{6}$ in the push-pull circuit are constructed by two-paralleled MOSFETs (Infineon Technologies BUZ341, $\left.R_{D S(O N)}=60[m \Omega]\right)$, respectively.

\section{B. S.C. charging/discharging operation}

Fig. 8 shows the operating waveforms of the push-pull circuit with the gate-emitter voltage of the controlled switch
$\mathrm{Q}_{1}$ in the S.C. charging mode. The inductor current $i_{L o}$, i.e. the super capacitor-charging current $i_{s c}$ is well regulated, and no significant current ripple is observable in the inductor current. In this mode, the reverse-recover current in the rectifier diodes $D_{5}$ of $S_{5}$ and $D_{6}$ of $S_{6}$ causes voltage spikes in the S.C. voltage $V_{S C}$. Those unnecessary voltage spikes, however, can easily be reduced by introducing synchronous rectification as described in the next subsection.

The steady-state operating waveforms of the push-pull circuit in the S.C. discharging mode along with the gate-emitter voltage of the controlled switch $\mathrm{Q}_{1}$ are shown in Fig. 9. There are current surges observed due to the hard-switching mode turn-off commutation in $\mathrm{Q}_{5}$ and $\mathrm{Q}_{6}$. These current spikes can be suppressed by a RCD snubber employed to $\mathrm{Q}_{5}$ and $\mathrm{Q}_{6}$ as mentioned later.

The simulated waveforms for the charging and discharging modes are additionally provided in Fig. 10 under the same circuit conditions as those of the experimental prototype. From the results of Figs. 8-10, the circuit operations theoretically described in Fig. 3 and 4 are practically verified.

As mentioned previously and depicted in Fig. 11(a), there are voltage and current surges generated due to the hardswitching mode turn-off operations in $\mathrm{Q}_{5}$ and $\mathrm{Q}_{6}$, which are inherent in the push-pull circuit operating by inverter mode [3]. As a solution, a RCD snubber is employed in the prototype DC-DC converter, and the operating waveforms with the passive snubber are shown in Fig. 11(b). The voltage peak stress is reduced by one-third with the aid of the snubber circuit.

Employment of soft switching lossless cells is a more effective solution from the view point of converter efficiency [10], [11].

\section{Effect of synchronous rectification}

The large charging/discharging currents in the S.C. have a significant impact on the conversion efficiency in the DCDC converter. Figs. 12(a) and 12(c) show the upscale current waveforms of $\mathrm{Q}_{5}$ in the S.C. charging mode when the pushpull circuit operates with the diode rectifiers $\left(D_{5}\right.$ and $\left.D_{6}\right)$. The current surges observed in the waveform of $I_{Q 5}$ are due to the reverse recovery of the diode $\mathrm{D}_{6}$ in the opposite-side active switch $\mathrm{Q}_{6}$. On the other hand, the current waveforms with the synchronous rectifications of $S_{5}$ and $S_{6}$ are depicted in Figs. 12(b) and 12(d), where no significant current surge occurs. Thus, the reverse recovery-related current surges as well as the ringing currents due to the parasitic capacitance of the MOFET switches can be suppressed effectively by introducing synchronous rectification in $\mathrm{Q}_{5}$ and $\mathrm{Q}_{6}$.

The conduction loss of $\mathrm{Q}_{5}\left(\mathrm{Q}_{6}\right)$ obtained by the synchronous rectification is compared with one by the diode rectifying mode in Fig. 13. It can be seen from the results that a reduction in the conduction loss can be achieved $60[\%]$ at $I s c=30[\mathrm{~A}]$ by synchronous rectification.

It has been verified that adopting a synchronous rectifier is useful not only for reducing the conduction loss but for precluding the occurrence of ringing in the push-pull circuit. 


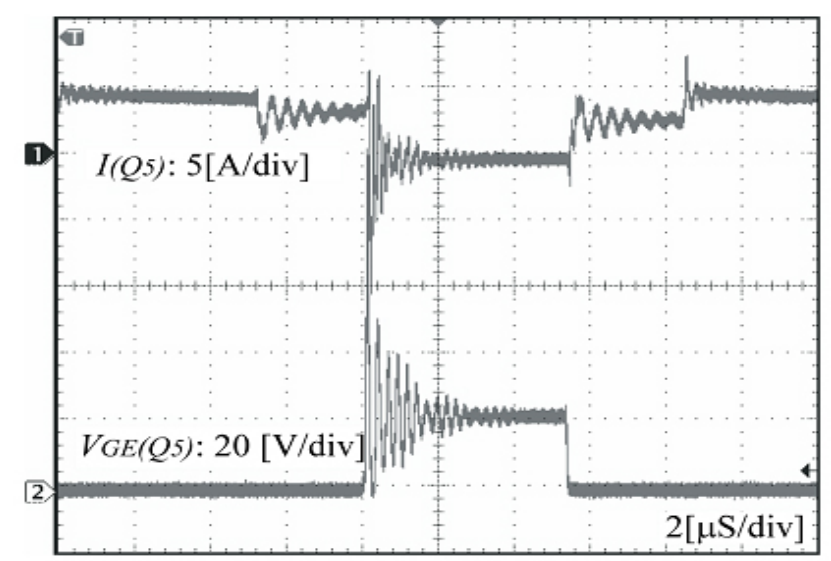

(a) Snubberless

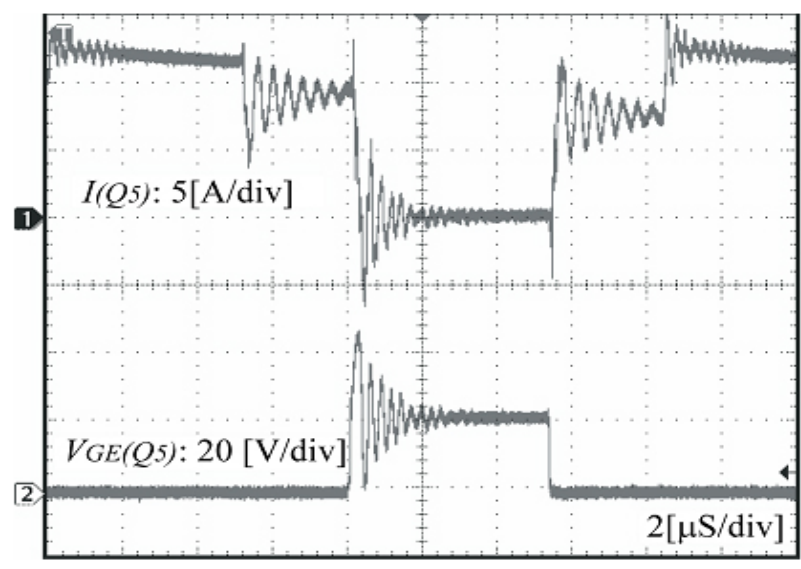

(b) RCD snubber

Fig. 11. Operating waveforms of active switch Q5 in S.C. discharging mode.

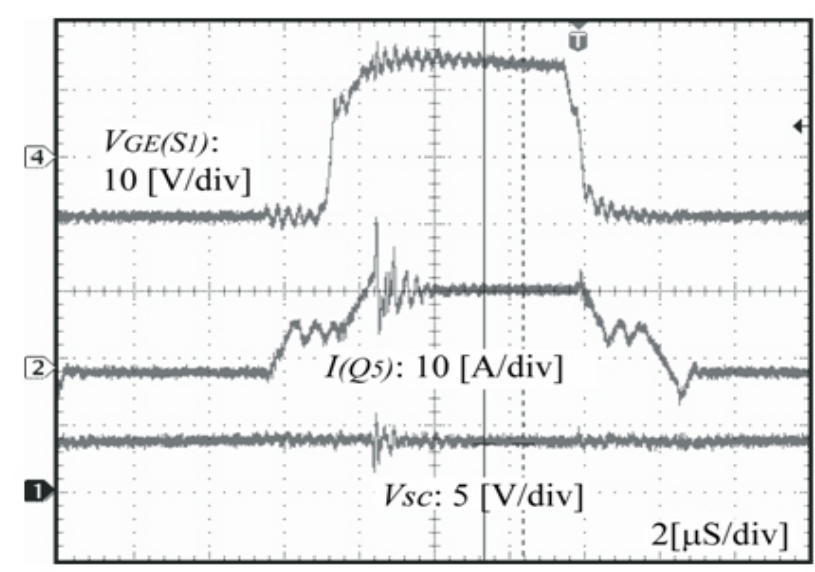

(a) diode rectifier $\left(I_{s c}=10[\mathrm{~A}]\right)$

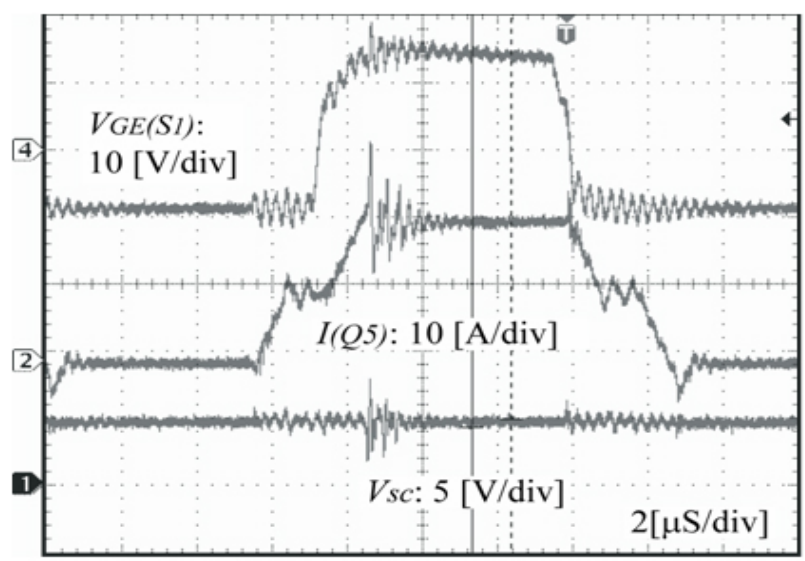

(c) diode rectifier $\left(I_{s c}=20[\mathrm{~A}]\right)$

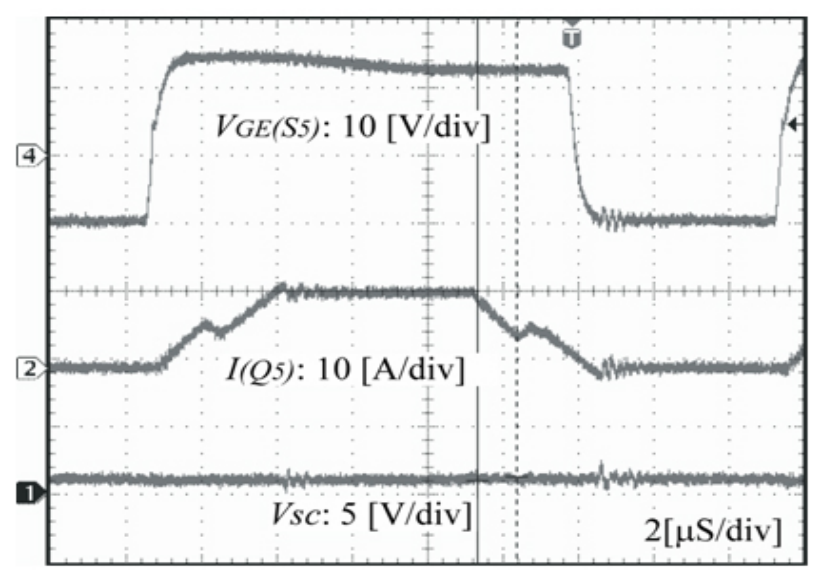

(b) synchronous rectifier $\left(I_{s c}=10[\mathrm{~A}]\right)$

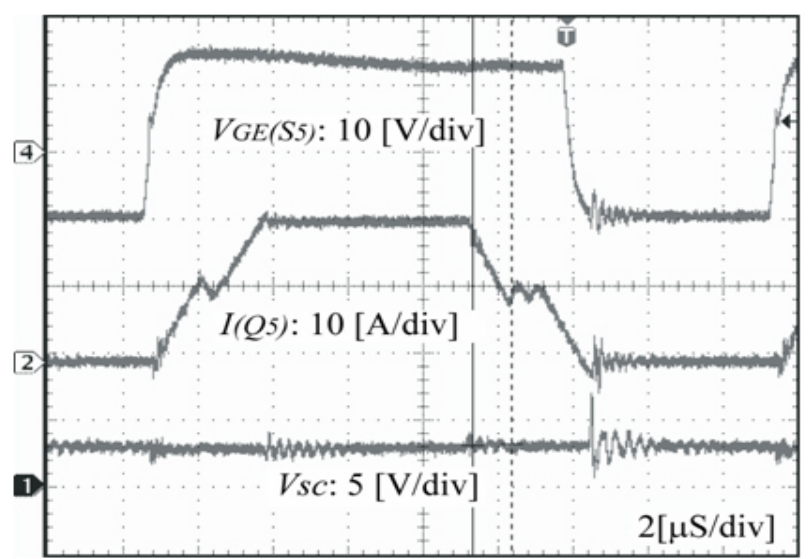

(d) synchronous rectifier $\left(I_{s c}=20[\mathrm{~A}]\right)$

Fig. 12. Operating voltage and current waveforms of active switch Q5 in S.C. charging mode.

\section{CONCLUSIONS}

This paper presents the performance evaluation of a high frequency transformer-link bidirectional DC-DC converter for a super capacitor bank in the low operating voltage condition. From the simulation and experimental results based on its experimental prototype, the following advantageous properties of the bidirectional DC-DC converter have been clarified:

- The push-pull circuit is useful for a low-voltage (fewer series connections) super capacitor and its bidirectional power-flow operation. 


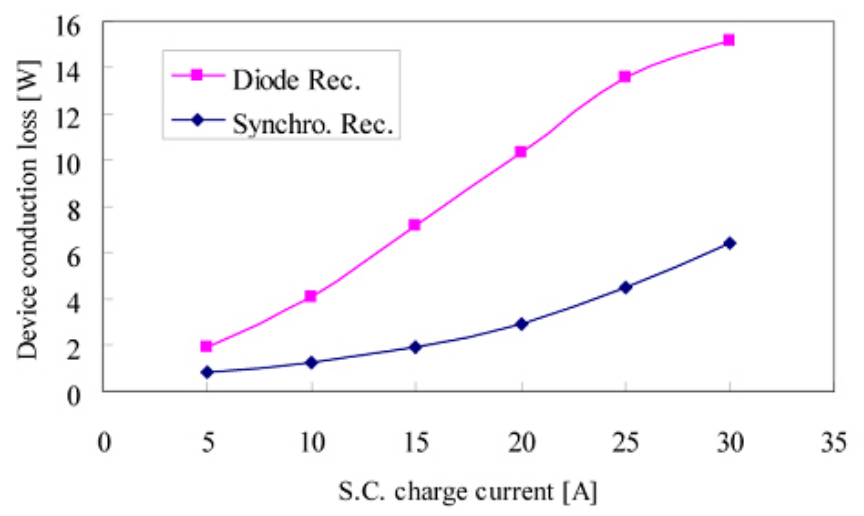

Fig. 13. Comparison on conduction losses of push-pull circuit (in S.C. charging mode).

- The wide range of charging and discharging operations of a super capacitor can be achieved seamlessly by a constant frequency phase-shifting PWM/overlapping PWM scheme.

- Power loss in the low voltage side circuit can be reduced effectively by employing synchronous rectification, thus improvement of the power conversion efficiency as well as the power density of the DC-DC converter can be expected.

In order to improve the switching performances and the conversion efficiency, employing the soft-switching technique into the push-pull circuit as well as the full bridge circuit might be the best approach. Evaluation and discussion of a softswitching bidirectional DC-DC converter utilizing the circuit topology presented here will be reported in the future.

\section{REFERENCES}

[1] A. Emadi, Y.J. Lee, and K. Rajashekara, "Power Electronics and Motor Drive in Electric, Hybrid and Plug-In Hybrid Electric Vehicles," IEEE Trans. Ind. Electron., Vol.55, No.6, pp.2237-2245, Jun. 2008.

[2] C.E. Kim, S.K Han, K.B. Park, and G.W Moon, "A New High Efficiency ZVZCS Bidirectional DC/DC Converter for HEV 42V Power Systems," Journal of Power Electronics, Vol. 6, No. 3, pp. 271-278, 2006.

[3] M. Jain, M. Daniele, and P.K. Jain, "A Bidirectional DC-DC Converter Topology for Low Power Applications," IEEE Trans. Power Electron., Vol. 15, No.4, pp. 49-54, Jul. 2000.

[4] D. Xu, C. Zhao, and H. Fan, "A PWM Plus Phase-shift Control Bidirectional DC-DC Converter," IEEE Trans. Power Electron., Vol.19, No.3, pp. 666-675, May 2004.

[5] T.C. Neugebauer and D.J. Perreaut, "Computer-Aided Optimization of DC-DC Converter for Automotive Applications," IEEE Trans. Power Electron., Vol.18, No.3, pp. 775-783, May 2003.

[6] G. Guidi, T. M. Undeland, and Y. Hori, "An Interface Converter with Reduced VA ratings for Battery-Supercapacitor Mixed Systems," Proc. 4th Power Conversion Convention Conference (PCC-Nagoya 2007), pp. 936-941.

[7] J. Zhang, R-Y. Kim, and J-S. Lai, "High-Power Density Design of a Soft-Switching High Power Bidirectional DC-DC Converter," Proc. 37th IEEE Power Electronics Specialists Conference (PESC 2006), pp. 21192125.
[8] F. Z. Peng, H. Li, G-J. Su, and J.S. lawler, "A New ZVS Bidirectional DC-DC Converter for Fuel Cell and Battery Applications," IEEE Trans. Power Electron., Vol. 19, No. 1, pp. 54-65, Jan. 2004.

[9] H.-J. Chiu and L-W. Lin, "A Bidirectional DC-DC Converter for Fuel Cell Electric Vehicle Driving Systems," IEEE Trans. Power Electron., Vol. 21, No. 4, pp. 950-958.

[10] E. Hiraki, K. Yamamoto, T. Tanaka, and T. Mishima, "An Isolated Bidirectional DC-DC Soft-Switching Converter for Super Capacitor Based Energy Storage Systems," Proc 38th IEEE Power Electronics Specialists Conference (IEEE-PESC07), pp. 390-395, Jun. 2007.

[11] K. F. Sayed and S.K. Kwon, "A Novel Quasi-Resonant Snubber-Assisted ZCS-PWM DC-DC Converter with High Frequency Link," Journal of Power Electronics, Vol.7, No.2, pp. 124-131, 2007.

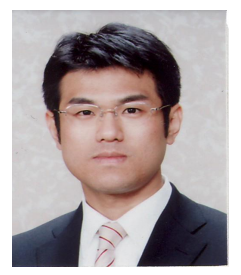

Tomokazu Mishima was born in Tokushima, Japan in 1975. He received a B.S., M.S. and Dr. Eng. in Electrical Engineering from The University of Tokushima, Japan, in 1999, 2001 and 2004, respectively. Since 2003, he has been with Department of Electrical Engineering and Information Science, Kure National College of Technology, Hiroshima, Japan, where he is currently an Assistant Professor and engages in the teaching of and research on power electronics. His main research interests are in the areas of soft switching DC-DC converters, high frequency inverters, automotive electric power systems and renewable energy technologies. He received the Best Paper Award in the 8th International Conference on IEEE Power Electronics and Drive Systems (IEEE-PEDS 2009). Dr. Mishima is a member of IEEE, the Institute of Electrical Engineering of Japan (IEEJ), the Japan Institute of Power Electronics (JIPE). He is also an advisory committee member of the JIPE and a professional member of the Investing Research and Development Committee in IEEJ.

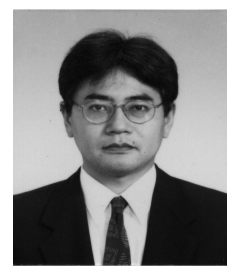

Eiji Hiraki was born in Hiroshima, Japan, in 1964. He received a Dr. Eng. in Electrical Engineering from Osaka University, Osaka, Japan in 2004. Since 1995 , he has been with the Department of Electrical and Electronics Engineering, Faculty of Engineering, Yamaguchi University, Japan, where he is currently an Associate Professor. His research interests include soft switching power converters, consumer power electronics and renewable energy technologies. Dr. Hiraki is a member of IEEE, IEEJ and JIPE.

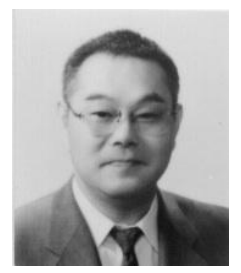

Mutsuo Nakaoka received a Dr. Eng. in Electrical Engineering from the Graduate School of Engineering, Osaka University, Osaka, Japan in 1981. From 1981 to 1995 , he was a Professor in the Department of Electrical and Electronics Engineering, Graduate School of Engineering, Kobe University, Hyogo, Japan. From 1995 to 2004, he was a Professor in the Department of Electrical and Electronics Engineering, Graduate School of Science and Engineering, Yamaguchi University, Japan. He is currently a Visiting Professor in Kyungnam University, Masan, Korea, and the University of Malaysia, Kuala Lumpur, Malaysia. His research interests are in the application and development of power electronics, energy electronics circuits and systems. He served as a Chairman of the IEEE Industrial Electronics Society Japan Chapter in 2001-2002. He received many distinguished paper awards such as the IEEE-ISIE 2009 Best Paper Award, the IEEE-PEDS 2009 Best Paper Awards, the 2004 IET-UK Compton Awards, the 2003 IEEE-IAS James Melcher Prize Paper Award, the 2001/2003 IEEEIECON Best Paper Award, the Best Paper Award of IATC 2006, the ICPE Best Paper Award and the ICEMS Best Paper Award. Prof. Nakaoka is a member of KIPE, IEEE, IEEJ, IEICE, JIPE and IEIEJ. 